Bol. Acad. peru. leng. 67. 2020 (221-259)

\title{
LOS TÉRMINOS PARA EL COLOR VERDE Y AZUL Y SU DESARROLLO SEMÁNTICO EN LA LENGUA ASHÁNINKA Y ASHÉNINKA
}

\section{THE TERMS FOR THE COLOURS GREEN AND BLUE AND THEIR SEMANTIC DEVELOPMENT IN THE ASHANINKA AND ASHENINKA LANGUAGES}

\author{
Oscar Augusto Solari Ruiz-Eldredge \\ Universidad Nacional Mayor de San Marcos \\ oscar.solari@unmsm.edu.pe \\ https://orcid.org/0000-0002-9143-700X
}

\section{Resumen:}

En esta investigación, se presenta el análisis de los términos cromáticos que conforman la categoría del color verde y del azul. Cada uno es el resultado de la codificación de la percepción de aspectos salientes de diversos referentes de la naturaleza, que se evidencia en la opacidad que presenta su estructura. Los fenómenos implicados en su reconstrucción se fundamentan a través de la teoría de la lexicalización y la metonimia, y de su pertenencia a la categoría a través de la teoría de los colores básicos y de los prototipos. En la categoría del verde, el término kenashiri se construye a partir de un fitónimo; matsiriari y natsiriari, a partir del aspecto de la coloración anormal en la piel, y eereki y eerepa, a partir de la coloración de los frutos cuando brotan. Asimismo, en la categoría del azul, asoriri es 
un hispanismo y kamachonkari se construye a partir de la percepción del aspecto de un ente o de su color con bajo grado de brillo.

Palabras clave: asháninka, reconstrucción, lexicalización, categoría, opacidad.

\section{Abstract:}

In this research, introduces the analysis of the chromatic terms that make up the category of green and blue colours is presented. Each one is the result of the codification of the perception of salient aspects of diverse referents of nature, which is evident in the opacity that shows its structure. The phenomena involved in their reconstruction are based on the theory of lexicalization and metonymy, and their belonging to the category through the theory of basic colours and prototypes. In the category of green, the term kenashiri is constructed from a phytonym; matsiriari and natsiriari, from the aspect of abnormal coloration in the skin, and eereki and eerepa, from the coloration of the fruits when they sprout. Likewise, in the category of blue, asoriri is a hispanism and kamachonkari is constructed from the perception of the appearance of an entity or its color with a low degree of brightness.

Key words: Asháninka, reconstruction, lexicalization, category, opacity.

Fecha de recepción:

Fecha de aceptación:
$10 / 02 / 2020$

$25 / 04 / 2020$

\section{Introducción}

Esta investigación forma parte del capítulo que explica las nociones del color verde y azul que se encuentra en la tesis Etnosemántica de los colores en la lengua asháninka - una visión cognitiva, sincrónica y diacrónica (Solari, 2019b). En este estudio, se identifica, sistematiza, describe y analiza morfológica y semánticamente cada cromónimo que pertenece a las categorías que conforman la noción de lo verde y azul en las lenguas asháninka y 
https://doi.org/10.46744/bapl.202001.008

ashéninka, que se fundamenta en la reconstrucción de las protoformas respectivas y los procesos de corte cognitivo que habrían ocurrido para su formación, con la finalidad de explicar el desarrollo semántico de cada término; además, se hace hincapié en las diferencias que presentan ambas lenguas en cuanto a la terminología per se y en la discusión de la validez de la existencia de la categoría que representa el color azul.

Para fundamentar la semántica de cada término, se hizo la reconstrucción respectiva con la ayuda de los cognados existentes en las lenguas nomatsigenga, matsigenka, kakinte y nanti.

Los estudios sobre la terminología cromática en lenguas peruanas se han enmarcado bajo el estructuralismo y, en las últimas dos décadas, se ha sumado el enfoque psicolingüístico en el análisis; sin embargo, aún son escasos. La información que se puede obtener sobre el léxico de este campo semántico en las lenguas asháninka y ashéninka se encuentra en investigaciones de índole lexicográfica ( $c f$. Wiener, 1880; Leclerc y Adam, 1890; Delgado, 1896, 1897; Sala, 1905; Touchaux, 1909; Kindberg, 1980; D. Payne, 1980; Heise, D. Payne, J. Payne y Vílchez, 2000; Cushimariano y Sebastián, 2008; MINSA, 2012; Muñoz, Quinchiza, García y Cochachi, 2012; Meneses, 2014), onomástica (cf. Romaní, 2004; Jacinto, 2009) y gramatical (cf. J. Payne, 1989; Mihas, 2010), donde se mencionan los términos de color de manera sucinta.

\section{La lengua asháninka y ashéninka}

El asháninka y el ashéninka forman parte de la macrolengua amazónica más hablada en el Perú. Según el documento Censos Nacionales 2017: XII de Población, VII de Vivienda y III de Comunidades Indígenas, del Instituto Nacional de Estadística e Informática (INEI), 68667 personas de cinco años a más reportan que su lengua materna es la asháninka (INEI, 2018: 203, como se cita en Solari, 2019b: 163 y 2020). Sin embargo, a partir de la información registrada en el documento III Censo de Comunidades Nativas 2017 - Resultados Definitivos, se afirma que la población total asháninka y ashéninka es de 111 558 habitantes (Jacinto, 2019). Entre los campos semánticos existentes en esta lengua, se encuentra el relacionado a los colores, y para el análisis de 
los componentes de cada término cromático — conocidos también como cromónimos - se requiere una perspectiva sincrónica y diacrónica enmarcada dentro de la teoría etnolingüística y cognitiva. Geográficamente, la lengua asháninka se habla en los departamentos de Junín y Cusco y la lengua ashéninka, en los departamentos de Junín, Pasco, Huánuco, Ucayali y en el estado brasileño del Acre (Solari, 2020).

En términos de filiación lingüística, la lengua asháninka y ashéninka forman parte de la familia lingüística arawak preandina (Solari, 2019b: 164). Fonológicamente, ambas lenguas comparten cuatro segmentos vocálicos breves y largos, que son /a/ y /a:/, /e/ y /e:/ (solo el dialecto ashéninka del Apurucayali presenta estas), /i/ e /ir/, y /o/ y /o:/, y catorce segmentos consonánticos, que son /p/, /t/, /k/, /ts/, /t $\mathrm{J} /, / \mathrm{s} /, / \mathrm{J} /, / \mathrm{h} /, / \mathrm{m} /, / \mathrm{n} /, / \mathrm{N} /, / \mathrm{j} /, / \mathrm{r} / \mathrm{y}$ los labiales $/ \beta / \mathrm{y} / \mathrm{w} /$ (el empleo de uno u otro depende del dialecto, aunque $/ \beta$ / es recurrente en asháninka) y los fonemas consonánticos palatalizados $/ \mathrm{p}^{\mathrm{j}} /, \mathrm{t}^{\mathrm{j}} / \mathrm{y} / \mathrm{k}^{\mathrm{j}} /$. No obstante, la lengua ashéninka también presenta los fonemas consonánticos aspirados $/ \mathrm{ts}^{\mathrm{h}} /, / \mathrm{t}^{\mathrm{h}} / \mathrm{y} / \mathrm{t} \mathrm{f}^{\mathrm{h}} /$; palatalizados $/ \mathrm{r}^{\mathrm{j}} /, / \mathrm{m}^{\mathrm{j}} /$, $/ \mathrm{w}^{\mathrm{j}} / \mathrm{y} / \beta^{\mathrm{j}} /$, y aproximantes $/ \mathrm{v} / \mathrm{y} / \mathrm{u} /$, aunque no todos los dialectos los comparten (Solari, 2020). Tipológicamente, la lengua presenta un orden básico Sujeto-Verbo-Objeto y Verbo-Sujeto-Objeto ( $f f$. Medina, 2011: 68), este último es el más empleado por aquellos hablantes que se encuentran menos expuestos al castellano.

\section{Marco teórico}

\subsection{La hipótesis de Sapir-Whorf}

El ser humano se encuentra inmerso en un ambiente que corresponde a la realidad experimentada. Asimismo:

necesita diseccionar la información recibida a través de mecanismos cognitivos de la organización de la información obtenida para que pueda orientarse y esta disección la hace clasificando los estímulos que percibe y las dimensiones en donde se encuentra, generalmente en base a las propiedades en común que tales estímulos poseen, siendo el resultado de la segmentación del mundo. (Solari, 2019a y 2020) 
https://doi.org/10.46744/bapl.202001.008

A través de la teoría del relativismo lingüístico, conocida también como la versión débil de la hipótesis de Sapir-Whorf, esta investigación se suscribe a la postura de que las operaciones mentales están influidas por el lenguaje, aunque esta no la determina (Solari, 2019a, 2019b: 354 y 2020).

\subsection{La categorización}

Cada estímulo, sea físico o dimensional, es clasificado sobre la base de categorías. A su vez, cada miembro obtiene una etiqueta léxica determinada porque el módulo del lenguaje codifica estas impresiones a través de la lengua (Solari, 2019a y 2020). La categorización es un fenómeno mental por el que se organiza la comprensión que se tiene del mundo, basada en la experiencia corpórea (Steinvall, 2002: 38, como se cita en Solari, 2019b: 101). Se caracteriza por ser variada y multiforme, lo que permite simplificar la infinitud de lo real a partir de la generalización y discriminación (Cuenca y Hilferty, 1999: 32, como se cita en Solari, 2019b: 88). Dentro de las taxonomías de los objetos concretos, las categorías están estructuradas de modo que generalmente entrañan un nivel de abstracción en el que pueden realizarse las disecciones más básicas de la categoría (Rosch et al., 1976: 384, como se cita en Solari, 2015: 89). Esta teoría parte de diversos estudios, principalmente en el área de la psicología y la antropología, en concreto, de experimentos sobre los colores, cuya clase formada es una categoría universal de carácter difuso y está codificada de manera distinta según cada lengua (Cuenca y Hilferty, 1999: 33, como se cita en Solari, 2019b: 101). Estos experimentos se emplearon para mostrar que la lengua tiene un efecto sobre el pensamiento (Brown y Lenneberg, 1954 y Ratner, 1989, como se cita en Mohammad, 2011: 98) y que no lo tiene (Bornstein, 1985, como se cita en Mohammad, 2011: 98). Esto implica aceptar la teoría del relativismo lingüístico en cuanto a la percepción y posterior codificación del ambiente a través del lenguaje (Solari, 2019a y 2020).

\subsection{La teoría de los prototipos}

El prototipo es el elemento de la categoría que comparte más atributos con el resto de los miembros de esta (Valenzuela, Ibarretxe y Hilferty, en prensa: 47-48, como se cita en Solari, 2020). Estos parecen ser solo 
aquellos miembros de una categoría que más reflejan la estructura de redundancia de la categoría como un todo (Rosch y Lloyd, 1978: 12, como se cita en Solari, 2019a). Se evidencia que algunas categorías naturales son entidades continuas, en vez de definidamente delimitadas, y algunas parecen estar estructuradas cognitivamente en términos que difieren en el grado en que los entes coinciden con los «buenos» ejemplos de la categoría, es decir, los más representativos (Rosch et al., 1976: 433, como se cita en Solari, 2019b: 95).

\subsection{La categorización cromática}

Solari (2020) afirma que la categorización cromática es la clasificación cultural de ciertos estímulos físicos que siguen a su recepción sensorial y procesamiento visual, las cuales son no relacionales y frecuentemente no discretas. Berlin y Kay (1969) proponen una teoría sobre la categorización cromática a partir de estudios que realizaron sobre los colores en las diferentes lenguas del mundo; postulan que existe un sistema universal de categorización del color compartido por todas las lenguas, bajo el argumento de que existen categorías básicas de color universales representadas por un término cromático prototípico con la mayor cantidad de características que definen la categoría.

Cada término cromático es el producto de la experiencia perceptual del poblador, cada vez que codifica las impresiones visuales obtenidas en la observación de los entes o un aspecto resaltante de estos con atención al color que tienen y, en la etapa actual de las lenguas del mundo, estos pueden ser el resultado de diferentes procesos cognitivos que implican metáforas, metonimias y la anexión y fosilización de lexemas y morfemas que expresan desde conceptos concretos hasta formas y dimensiones mediante la lexicalización (Solari, 2020). Estas impresiones visuales son clasificadas sobre la base de, al menos, una de sus tres dimensiones: el matiz (en inglés, hue), el brillo (en inglés, bright) y la saturación (en inglés, saturation). En la antigüedad, la delimitación y clasificación de los colores se hacía sobre la base del grado mayor o menor de brillo; no obstante, en la mayoría de las lenguas que se hablan actualmente, la clasificación se hace basada en grupos tonales. Esa impresión visual que ingresa a nuestro cerebro a través de la vista y a la que posteriormente le asignamos un significado se llama cromema (Solari, 2020). 
https://doi.org/10.46744/bapl.202001.008

\subsection{El cromema}

El cromema es el signo visual que identifica el color (Parodi, 2002: 57, como se cita en Solari, 2019: 57). El hombre percibe cromemas a través de los colores que tienen los entes y las dimensiones de la naturaleza que se encuentran a su alrededor, en presencia de luz. Los cromemas, cuando son reconocidos, se les agrupa por similaridad visual y se les asigna etiquetas léxicas, generalmente basadas en el tono que, de cierto modo, en la mayoría de lenguas indoeuropeas y algunas habladas en Asia, concuerdan con la organización «convencional» de los tonos observados en el arcoíris. Al grupo de cromemas más prototípico o familiar le será asignado el cromónimo prototípico; al grupo de cromemas menos familiares para la percepción humana le serán asignados cromónimos derivados del prototípico o cromónimos secundarios no prototípicos, dependiendo del grado de brillo y saturación del contexto (Solari, 2019b: 57).

Por ejemplo, en las hojas de los árboles se percibe una infinidad de cromemas que los hispanohablantes denominan generalmente verde, algunos de ellos son $\mathbf{\square}, \mathbf{\square}, \mathbf{\square}, \mathbf{\square}$ y $\mathbf{\square}$ (en castellano, estos cronemas se denominarían verde claro, verde limón, verde oscuro, verde olivo y verde olivo oscuro, respectivamente, aunque estos nombres variarían según quien los observe), que consideran también la especie del árbol (porque pueden existir hojas de color verde azulado) o de la estación (pueden cambiar a una coloración rojiza o marronácea). Estos y los otros cromemas de la categoría que corresponde a la noción del color verde han sido agrupados y codificados en el cerebro gracias al aprendizaje y a la experiencia a través de etiquetas léxicas. El cromema más prototípico de esta categoría es el que visualmente se asemeja al color del pasto; por lo tanto, el cromema - (y los cromemas que difieren muy mínimamente en el grado de brillo) es etiquetado bajo el término prototípico que, en el caso de la lengua castellana, es verde (Solari, 2019b: 57-58). En otro grupo de cromemas, para los hispanohablantes, $\mathbf{\square}$ son denominados bajo un solo término (azul) dentro de la categoría que corresponde a la noción del color azul; sin embargo, en otras lenguas, estos cromemas son denominados bajo dos términos, como ocurre en italiano y en ruso, donde la diferencia recae en el grado de brillo (Solari, 2019b: 58). 
En el mundo, existen infinitos cromemas que son etiquetados lexicalmente de acuerdo con el grupo de cromemas almanecenados a través de una información-respuesta neuronal en el cerebro - por adquisición - y de acuerdo con la lengua del hablante. Una lengua puede etiquetar determinados grupos de cromemas adquiridos y aprendidos, aunque eso no significa que sea incapaz de aprender otros grupos de cromemas que estén bajo una etiqueta lingüística distinta en otras lenguas (Solari, 2019b: 58).

\subsection{La lexicalización}

La lexicalización es el proceso mediante el cual una expresión que previamente se obtenía o recibía acceso por medios gramaticales o analíticos se archiva como un bloque en la memoria o diccionario mental, y se emplea de manera global, sin la necesidad de un previo análisis (Elvira, en prensa: 4, como se cita en Solari, 2019b: 136).

\section{Métodos}

Este estudio es de carácter cualitativo, bajo un enfoque sincrónico y diacrónico. Se trabajó con veinticuatro colaboradores lingüísticos asháninkas y ashéninkas con diverso grado de bilingüismo y que habitan en las zonas geodialectales del río Tambo (TB), río Ene (EN), río Apurímac (RA), Satipo-Bajo Perené (SA) (zona geodialectal asháninka), Alto Perené (PE), río Pichis (PI) y Gran Pajonal (GP) (zona geodialectal ashéninka), entre personas dedicadas a la agricultura, docentes del programa de la Educación Intercultural Bilingüe y otras con estudios superiores, cuyo rango de edades fluctúa entre los veinte y setenta y cinco años. Se agregó a este estudio datos lexicográficos del dialecto ashéninka del Apurucayali (AP). Los datos se obtuvieron de entrevistas semiestructuradas formuladas que constaban de preguntas indirectas.

Los datos se extrajeron de las entrevistas hechas a los colaboradores lingüísticos y de las consultas a materiales lexicográficos previos. En las entrevistas se empleó la tabla de colores de Munsell, instrumento que consiste en un rectángulo cuadriculado, en cuya primera columna se 
https://doi.org/10.46744/bapl.202001.008

percibe un degradé monócromo desde el color blanco hasta el negro en diez cuadrados, y en el conjunto de las otras columnas se observa un degradé polícromo que, desde la perspectiva hispanohablante, se perciben los siguientes colores de izquierda a derecha: rojo, anaranjado, amarillo, verde, azul, celeste, púrpura, rosa, gris y marrón. También se empleó en la investigación la plantilla de colores del sistema HEX para sitios web HTML (CSS3) y una imagen del espectro cromático en formato RGB; no obstante, para este artículo solo se ha tomado en cuenta la tabla de Munsell por cuestiones de espacio.

Para el caso de esta investigación donde se analiza la noción del color negro, se le indicó al colaborador que marcara el grupo de cuadrados que indicaran los cromemas ligados a las etiquetas léxicas que los pobladores asháninka emplean en su lengua para denominar este color.

Los materiales escritos consultados fueron diversos vocabularios publicados a finales del siglo xIx e inicios del siglo $\mathrm{xx}$, donde se evidencia en cierto modo el grado de vitalidad del cromónimo. También fueron consultados, a modo de antecedentes, diccionarios contemporáneos de la lengua asháninka y ashéninka y tesis referentes a la onomástica de estas dos lenguas amazónicas donde se diera cuenta del registro de estos términos.

\section{Resultados y análisis}

\subsection{Categorización de los colores en la lengua asháninka y ashé- ninka}

El color es un descriptor visual cuya propiedad está basada en los contrastes percibidos a través de la luz (Solari, 2019b: 48-52; 2020). Es un estímulo visual que permite la orientación, debido a que inconscientemente se otorgan propiedades basadas en las concepciones culturales propias de la respectiva sociedad a la cual se pertenezca. En la lengua asháninka y ashéninka, se reconoce la existencia de colores, a pesar de que no exista un término genérico hiperonímico definitivo que agrupe a todo este campo léxico; sin embargo, existe un término que presenta 
una acepción que refiere a la presencia física del color de un ente. A partir de la aplicación de la teoría de los términos de color básicos (Berlin y Kay, 1969), en estas dos lenguas amazónicas se presentan las siguientes categorías cromáticas (Solari, 2019b: 192-193, 2020):

- Categoría ALBUS: encierra a un grupo de cromemas bajo el término básico kitamarori. Es la categoría cuyo término básico en castellano es blanco.

- Categoría NIGER: encierra a un grupo de cromemas bajo el término básico kisaari. Es la categoría cuyo término básico en castellano es negro.

- Categoría RUSSUS: encierra a un grupo de cromemas bajo el término básico kityonkari. Es la categoría cuyo término básico en castellano es rojo.

- Categoría FLAVUS: encierra a un grupo de cromemas bajo el término básico kiteriri. Es la categoría cuyo término básico en castellano es amarillo.

- Categoría VIRIDIS: encierra a un grupo de cromemas bajo el término básico kenashiri. Es la categoría cuyo término básico en castellano es verde.

- Categoría CAERULEUS: encierra a un grupo de cromemas bajo el término básico asoriri y, solo en el dialecto asháninka del río Apurímac, bajo el término básico kamachonkari. Es la categoría cuyo término básico en castellano es azul.

- Categoría SPADIX: encierra a un grupo de cromemas bajo el término básico kamarari. Es la categoría cuyo término básico en castellano es marrón.

- Categoría PURPUREUS: encierra a un grupo de cromemas bajo el término básico koricha. Es la categoría cuyo término básico en castellano es púrpura o morado.

- Categoría RAVUS: encierra a un grupo de cromemas bajo el término básico samampori. Es la categoría cuyo término básico en castellano es gris o plomo.

Los nombres de cada categoría cromática se han colocado en mayúsculas. Esto se va a explicar a través del siguiente ejemplo. El nombre de la 
https://doi.org/10.46744/bapl.202001.008

categoría que agrupa las tonalidades del color amarillo es el cromónimo más empleado para denominar el grupo de cromemas semejantes al color de los pétalos del girasol, del palillo o cúrcuma molida, o de algún otro referente que se considere el color amarillo ideal según la cultura de la lengua en cuestión (en este caso, el término que agrupa al cromema $\square$ y los cromemas derivados como $\square, \square, \square$ y $\square$ ). Si se emplea el inglés para la etiquetación de las categorías, se denominaría «categoría YELLOW»; si se emplea el castellano, se denominaría «categoría AMARILLO»; si se emplea el francés, se denominaría «categoría JAUNE». La regla más importante que debe cumplirse para la etiquetación de las categorías en una lengua en particular es que tengan términos propios y no derivados para los cromónimos blanco, negro, rojo, amarillo, verde, azul, marrón, púrpura, rosa, naranja y gris. Esto se debe a que se trabaja con un metalenguaje que, a través de términos cromáticos genéricos, sea en la lengua que fuere, permite la clasificación de infinidad de colores en familias de colores, a través de solamente once categorías.

Generalmente, en los artículos donde se aborda la temática del color, se emplea el inglés como una lengua «neutra» para etiquetar cada categoría; empero, esto ha generado muchas críticas por parte de lingüistas como Anna Wierzbicka (Kuehni, 2008) por el hecho de que se considere que esta lengua es la más objetiva, en el sentido de expresar las ideas de la ciencia por su alto desarrollo conceptual en ese campo. En este artículo, se emplea el latín para la etiquetación de cada categoría cromática, a fin de evitar una polémica en cuanto a una postura «anglocentrista» o «hispanocentrista». No obstante, el autor de esta investigación no está en contra de que se siga empleando el inglés para tal fin.

La lengua asháninka y la ashéninka presentan estructuras muy similares tanto en el léxico como en los afijos flexivos y, en menor medida, en los afijos derivativos. Empero, la diferencia se evidencia desde la disminución del número de categorías hasta la no coincidencia en los límites visuales de un cromónimo con respecto a otro, evidencia encontrada en este artículo. Se expone en este estudio el caso de la categoría VIRIDIS y la categoría no estable CAERULEUS, los cromónimos que conforman esta categoría y el desarrollo semántico de cada uno. 


\subsection{Categoría VIRIDIS en la lengua asháninka y ashéninka}

En la lengua asháninka y ashéninka, esta categoría tiene como cromónimo básico el término kenashiri (solamente en el dialecto ashéninka del Apurucayali, se tiene la variante kinashiri) y como cromónimos secundarios, los términos matsiriari —y la variante ashéninka natsiriari- y eereki — junto con su variante morfológica eerepa-. Empero, la categoría VIRIDIS se escinde en dos en el macrodialecto ashéninka y solamente algunos hablantes (en especial, los que hablan el dialecto de Satipo-Bajo Perené y del río Tambo) están adoptando este proceso de escisión categorial. Esta escisión resulta en la aparición de las categorías VIRIDIS y una adicional, CAERULEUS, las cuales agrupan una serie de colores relacionados al verde y azul (esta última definida bajo el cromónimo básico asoriri, un hispanismo que proviene de azul). Solamente en el dialecto asháninka del río Apurímac, el cromónimo básico de la categoría CAERULEUS es kamachonkari.

En la lengua asháninka, la categoría VIRIDIS abarca los siguientes cromemas en la tabla de colores de Munsell:

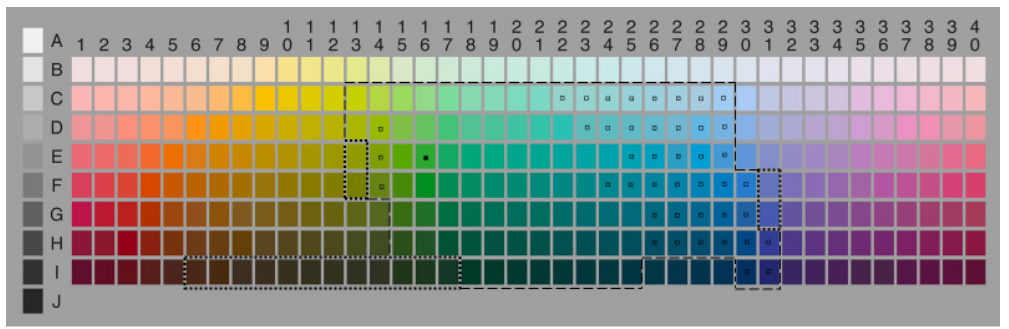

Figura 1. Representación del mapa cromático de la lengua asháninka en donde se muestra la ubicación cromométrica de kenashiri en la tabla de colores de Munsell. El símbolo representa el punto focal de kenashiri, a su vez, el cromema más prototípico. El símbolo $\square$ representa que al menos un entrevistado lo consideró dentro de la etiqueta lingüística en cuestión. Las áreas encerradas con líneas punteadas representan al grupo de cromemas compartidos por otras categorías cromáticas. Adaptado de Solari (2019b: 276). 
https://doi.org/10.46744/bapl.202001.008

A partir de la observación de este mapa cromático, los hablantes de la lengua asháninka relacionan los cromemas que los hispanohablantes denominan verde con la etiqueta léxica kenashiri y matsiriari; asimismo, algunos hablantes incluyen los cromemas denominados por los hispanohablantes azul, los que denominan también kenashiri y matsiriari. En términos de cromemas, la extensión del color básico en la lengua asháninka perteneciente a la categoría VIRIDIS abarca desde del grupo de tonalidades similares al de las hojas de las plantas, es decir, los cromemas $\square, \boldsymbol{\square}, \boldsymbol{\square}, \boldsymbol{\square} \mathbf{y} \boldsymbol{\square}$, donde solamente kenashiri es el cromónimo básico (Solari, 2019b: 279) y puede extenderse hacia los cromemas que están bajo una tonalidad azulina como $\square$, $\square, \square, \square$ y $\square$. Por ello, la categoría VIRIDIS en la lengua asháninka podría llamarse en inglés «categoría GRUE», término compuesto por las palabras green ('verde') y blue ('azul'), que indicaría que el color grue abarca las gamas de los colores verde y azul. Esto se cumple, sobre todo, en los hablantes bilingües que tienen menos contacto con la población hispanohablante y los monolingües. Para algunos hablantes del asháninka, en especial, los que se encuentran más expuestos al castellano, los cromemas $\mathbf{\square}, \mathbf{\square}, \mathbf{\square}$, y dejan de estar bajo la etiqueta lingüística kenashiri; es decir, este grupo poblacional concibe la existencia de los cromemas azulinos como separados de los verdes y, en no pocas ocasiones, estos cromemas no reciben etiqueta léxica alguna. Ocasionalmente, algunos hablantes también llegan a relacionar los cromemas similares al color marrón como $\mathbf{\square}, \mathbf{\square}, \mathbf{\square}$ y con el cromónimo kenashiri, a pesar de que los tres últimos cromemas y sus similares comparten categoría con SPADIX, cuyo cromónimo básico es kamarari. 
En la lengua ashéninka y en el dialecto asháninka del río Apurímac, la categoría VIRIDIS abarca los siguientes cromemas en la tabla de colores de Munsell:

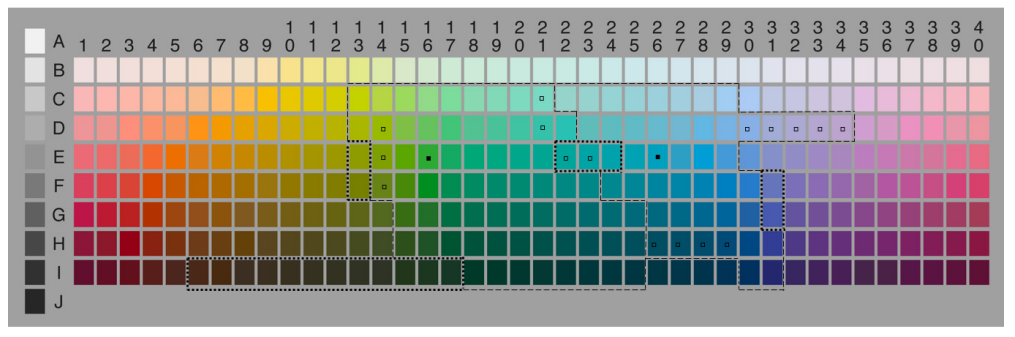

Figura 2. Representación del mapa cromático de la lengua ashéninka donde se muestra la ubicación cromométrica de kenashiri y asoriri (y en el caso del dialecto asháninka del río Apurímac, kamachonkari) en la tabla de colores de Munsell. En la mitad del área delimitada a la izquierda, el símbolo representa el punto focal de kenashiri, a su vez, el cromema más prototípico. En la mitad del área delimitada a la derecha, el símbolo representa el punto focal de asoriri y de kamachonkari, a su vez, el cromema más prototípico. El símbolo $\square$ representa que al menos un entrevistado lo consideró dentro de la etiqueta lingüística en cuestión. Las áreas encerradas con líneas punteadas representan al grupo de cromemas compartidos por otras categorías cromáticas. Adaptado de Solari (2019b: 277).

Los hablantes del ashéninka y del dialecto asháninka del río Apurímac hacen una partición del que abarca desde los colores que los hispanohablantes denominan verde hasta los colores que denominan azul, por el hecho de que reconocen la existencia de los cromemas del azul bajo la etiqueta léxica asoriri, producto de una adaptación del término hispano a la lengua (Solari, 2019b: 277). Es decir, en la antigüedad, en la lengua ashéninka habría existido solamente la categoría VIRIDIS y, posteriormente, esta sufrió una escisión, lo que la dividió en VIRIDIS y CAERULEUS. Esto se habría debido a factores socioculturales, como la adopción del tinte azul para emplearse en las prendas de vestir y la necesidad de diferenciar este color de aquellos relacionados a las 
https://doi.org/10.46744/bapl.202001.008

tonalidades verduzcas que son percibidas en las plantas. Otra de las múltiples razones habría sido la incursión temprana de población foránea en el territorio donde actualmente se hallan los hablantes del ashéninka, lo que generó tempranamente la necesidad de diferenciar ambos colores (Solari, 2019b: 277). En casos excepcionales, asoriri podría compartir categoría con NIGER, cuyo cromónimo básico es kisaari, aunque visualmente estas tonalidades que podrían ser asoriri también podrían ser potsitari dentro de aquella categoría, pues una de las tonalidades que califica como este último término son aquellas que los hispanohablantes denominarían marrón oscuro y negro. Para algunos hablantes del ashéninka, el término kisaari (el cromónimo que refiere al color negro) también podría relacionarse con el grupo de cromemas denominados en castellano bajo el término compuesto azul oscuro. Esto ya se había evidenciado en las acepciones de kisaari en los vocabularios asháninka-castellano publicados a finales del siglo xix e inicios del siglo xx (cf. Leclerc y Adam, 1890: 103 y Sala, 1905: 23), además de que esta acepción se comparte parcialmente con su cognado en la lengua nomatsigenga ( $c f$. Shaver, 1996: 182).

Solamente en el dialecto asháninka del río Apurímac, el cromónimo básico de la categoría CAERULEUS es kamachonkari, del cual sus límites son definidos. En el hecho de que modifiquemos la tabla cromática de Munsell para que haya una fila adicional inferior (es decir, la fila correspondiente a J), se evidenciaría que algunos de los cromemas referidos bajo la etiqueta kenashiri, asoriri y kamachonkari podrían compartir categoría con NIGER, por el hecho de que visualmente se asemejan a kisaari. 


\subsection{Estructura interna de la categoría VIRIDIS}

A través de la teoría de los prototipos, se presenta el siguiente esquema donde se expone la estructura interna de esta categoría:

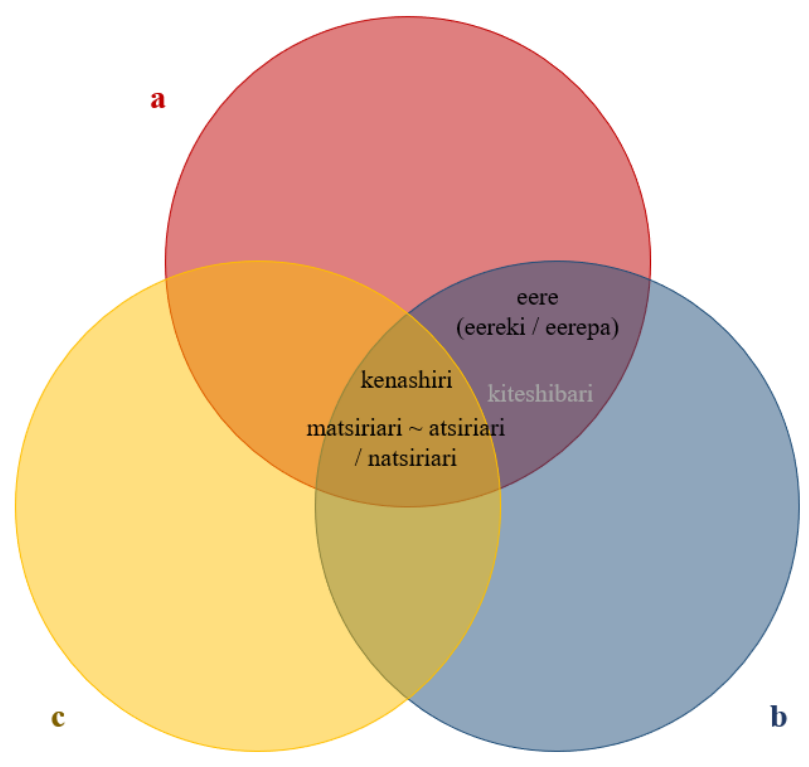

Figura 3. Estructura interna de la categoría VIRIDIS según la teoría de prototipos. Los atributos de esta categoría están representados a través de conjuntos, donde «a» equivale a los cromónimos cuyos cromemas pertenecen al campo del color verde; «b» equivale a los cromónimos cuya aplicación calificativa a diferentes contextos no es limitada, $\mathrm{y}$ «c» equivale a los cromónimos que no limitan con otras categorías. Adaptado de Solari (2019b: 282).

En esta categoría, el cromónimo kenashiri es el miembro más prototípico, por tanto, es también el cromónimo básico porque es el primer término que aparece en la mente del hablante asháninka y ashéninka cuando debe calificar un ente en el que percibe el color 
https://doi.org/10.46744/bapl.202001.008

verde. No obstante, según la teoría de los colores básicos de Berlin y Kay, este término no debería ser básico por el hecho de que su lexema (es decir, <kenashi $>$ ) hace referencia a un ente que, en este caso, es la hierba de la panca panca (Philodendron sp., según García Zavaleta [1987: 65]; aunque, según Luziatelli, Sørensen, Theilade y Mølgaard [2010: VII], es Xanthosoma poeppigii Schott). El cromónimo asháninka matsiriari (cuya variante es atsiriari) y el ashéninka natsiriari (variante dialectal de matsiriari por labialización del segmento nasal del término) son términos secundarios que califican entes de color verde, en especial, si son de origen vegetal. Califican el verdor de las plantas, sus partes y todo lo relacionado a ellas. Estos términos, si no fuera por esta restricción, serían los básicos de la categoría VIRIDIS (Solari, 2019b: 282). En el caso de los términos derivados del lexema <eere>, eereki y eerepa se restringen a calificar el verdor de la cáscara de los frutos que recién se encuentran brotando y que están en un estado temprano de desarrollo (Solari, 2019b: 282). Por último, aparece kiteshibari, cromónimo que lexicaliza el grupo de cromemas que se encuentran entre , $\square$ у $\square$, colores percibidos que los hispanohablantes denominarían desde pálido, amarillento hasta verde limón claro. Comparte categoría con FLAVUS, que agrupa los términos relacionados al color amarillo, razón por la cual es solamente un término secundario de la categoría VIRIDIS. Sin embargo, este cromónimo no se trata en este artículo por el hecho de que el lexema $<$ kite $>$, al que se fosilizaron los clasificadores $<-$ shi $>$ y $<$-ba $>$, proviene del lexema del protoarawak preandino */kite/, el que evoluciona, entre otros términos, al cromónimo básico de la categoría FLAVUS (aquella que clasifica los términos que hacen referencia al color amarillo): kiteriri.

\subsection{Etimología y desarrollo semántico del término básico de la ca- tegoría VIRIDIS}

El término básico de la categoría VIRIDIS en la lengua asháninka y ashéninka es kenashiri. Solamente en el dialecto ashéninka del Apurucayali es kinashiri. 
Tabla 1

Cuadro comparativo del término básico para la categoría VIRIDIS. Adaptado de Solari (2019b: 283)

\begin{tabular}{|c|c|c|c|c|c|c|c|c|}
\hline \multirow{2}{*}{ Castellano } & \multicolumn{6}{|c|}{ Macrolengua asháninka } \\
\cline { 2 - 9 } & \multicolumn{3}{|c|}{ Lengua asháninka } & \multicolumn{5}{c|}{ Lengua ashéninka } \\
\cline { 2 - 8 } & SA & TB & EN & RA & PE & PI & GP & AP \\
\hline \multirow{2}{*}{ verde } & kenashiri & kenashiri & kenashiri & kenashiri & kenashiri & kenashiri & kenashiri & kinashiri \\
\hline
\end{tabular}

Para la reconstrucción de este cromónimo, debe recurrirse a los cognados existentes (totales o parciales) en las otras lenguas arawak preandinas:

Tabla 2

La reconstrucción del término básico de la categoría VIRIDIS en la lengua asháninka y ashéninka a partir del término propio en estas dos lenguas y sus cognados en las lenguas kakinte, nomatsigenga y matsigenka, representados en fonemas. Adaptado de Solari (2019b: 283)

\begin{tabular}{|c|c|c|c|c|c|c|c|}
\hline $\begin{array}{l}\text { Caste- } \\
\text { llano }\end{array}$ & $\begin{array}{l}\text { Ashé- } \\
\text { ninka }\end{array}$ & $\begin{array}{l}\text { Ashánin- } \\
\text { ka }\end{array}$ & Kakinte & $\begin{array}{c}\text { Nomatsi- } \\
\text { genga }\end{array}$ & $\begin{array}{l}\text { Matsi- } \\
\text { genka }\end{array}$ & Nanti & $\begin{array}{c}\text { Protoarawak } \\
\text { preandino }\end{array}$ \\
\hline verde & $\begin{array}{l}\text { /kenajiri/ } \\
/ \text { kinajiri/AP }\end{array}$ & /kenajiri/ & $\begin{array}{c}\text { /kenajiri/ } \\
\text { ¿? }\end{array}$ & /kinasiri/* & - & - & $\begin{array}{c}* / \text { kina }[i-\Gamma i / \\
\downarrow\end{array}$ \\
\hline $\begin{array}{l}\text { esp. de } \\
\text { hierba }\end{array}$ & /kenaji/ & /kenajil & $\begin{array}{c}\text { /kenaji/ } \\
\text { ?? }\end{array}$ & /kinasi/ & /kenajil & /kenafi/ & */kịna-ji/ \\
\hline
\end{tabular}

En las lenguas asháninka y ashéninka — considerando que ambas evolucionaron de la hipotética lengua llamada protoasháninka y esta, a su vez, del protoarawak preandino-, la reconstrucción de kenashiri implica sucesivos procesos de lexicalización y, a la par, un cambio semántico unidireccional. Se postula que el cromónimo básico kenashiri fue el producto de la adjetivación del término al que hace referencia kenashi, la hierba medicinal panca panca (Xanthosoma poeppigii Schott), que concentra su semántica en la tonalidad verde de las hojas de esa planta. 
https://doi.org/10.46744/bapl.202001.008

El látex que se extrae del tallo de la panca panca es empleado generalmente para curar cicatrices por corte. Los pobladores la emplean, además, para calmar el dolor dental colocando en la zona del diente donde se encuentra la caries (García Zavaleta, 1987: 64, como se cita en Solari, 2019b: 284). El fitónimo kenashi habría tenido el mismo significado en protoasháninka.

Mediante la reconstrucción del término en conjunto con los cognados en las lenguas kakinte, nomatsigenga, matsigenka y nanti, kenashi (de donde parte el adjetivo calificativo kenashiri) —expresado fonémicamente como /kenaji/ - habría sido el resultado de la lexicalización de dos morfemas, donde el protomorfema */kịna/ (el símbolo/ị/ representa un fonema vocálico alto anterior no redondeado que, en una etapa posterior, tiende a relajarse hasta convertirse en una vocal media, que conserva su rasgo de anterioridad y se evidencia en todas las lenguas arawak preandina, menos en nomatsigenga y en el dialecto ashéninka del Apurucayali) habría hecho referencia a cualquier planta medicinal o alguna cuya especie no se determinó y cuya característica era el color verduzco-azulino de sus hojas. Esto se debe a que en las lenguas arawak preandinas, este lexema fosilizado contenía la noción de una planta medicinal, aunque en estas lenguas no había coincidencia en la especie. El clasificador de hoja (a su vez, el clasificador de entes que terminan en punta como las hojas de las plantas) <-shi > en asháninka y ashéninka indica que kenashi (y también kenapashi) hace referencia a las hojas de la panca panca; sin embargo, algunos hablantes lo relacionan con la hoja de la pituca (Colocasia esculenta), que lleva el apelativo de 'oreja de elefante' (Solari, 2019b: 283). Cuando el poblador asháninka tuvo la necesidad de calificar los entes que son verdes, generó una adjetivación del sustantivo kenashi para este color, que tuvo como foco de concentración el verdor de las hojas (Solari, 2019b: 285). Este proceso ya se evidenciaba a finales del siglo XIx con el registro de Leclerc y Adam (1890: 103) del término «quina-chiri» (escrito en la ortografía oficial como kenashiri y kinashiri, según el dialecto), que refiere el color verde, y a inicios del siglo xx con el registro de Delgado (1897: 351) de los términos «kitzari» (en la lengua ashéninka, kitzari) y «quinachirı» (kenashiri o kinashiri según el dialecto) para la misma referencia cromática. De estos dos últimos términos, el primero quedó en obsolescencia. 
Para la reconstrucción del cromónimo básico kenashiri, debe partirse de los cognados arawak preandinos. Aquellos que cumplen con este precepto son los términos de la lengua asháninka (/kenafiri/), ashéninka (/kenafiri/ y la variante/kina jiri/) y del nomatgigenga (/kinasiri/). Sin embargo, en nomatsigenga, el cognado refiere a una especie de árbol (Shaver, 1996: 180) que, por las otras referencias del lexema de este término con función sustantiva (es decir, /kinasi/), está relacionado con las hojas del tubérculo llamado pituca (Colocasia esculenta); esa misma acepción se repite en el cognado sustantivo nanti / kena $\mathrm{ji} /$. Si bien hasta el día de hoy no se ha publicado un diccionario del kakinte, se deduce, por las pocas fuentes disponibles, que el cognado en su forma sustantiva es /kena $\mathrm{i}$ /, que haría la misma referencia. En asháninka, el sustantivo / kena $\mathrm{i}$ / también refiere a una especie de planta, la panca panca, y solo para algunos hablantes, la pituca. Una de las especies de pituca en el nomatsigenga es registrada por Shaver, 1996: 298) como «quina» (representado fonémicamente como/kina/), lo que nos sugiere que, en realidad, la forma kenashi (o kinashi) significaría subyacentemente 'la hoja de una especie de tubérculo o hierba' (Solari, 2019b: 284). En la lengua matsigenka, /kenafi/ refiere una especie de hierba llamada patquina, cuyo nombre científico es Anthurium uleanum Engl. var. nanayense Croat según Lingán (2006: 702).

El cambio semántico en el desarrollo del término kenashiri en la lengua asháninka y ashéninka (y de kinashiri en el dialecto ashéninka del Apurucayali) es el siguiente (Solari, 2019b: 286):

$$
\begin{aligned}
& \text { 'planta } \\
& \text { medicinal }>\begin{array}{l}
\text { 'hoja de planta } \\
\text { medicinal' }
\end{array}
\end{aligned} \quad \begin{aligned}
& \text { 'hoja de panca } \\
& \text { panca' } \\
& \text { 'hoja de pituca' }
\end{aligned} \quad \begin{aligned}
& \text { 'color de la hoja } \\
& \text { de panca panca' } \\
& \text { 'color de la hoja } \\
& \text { de pituca' }
\end{aligned}
$$

El desarrollo unidireccional evidenciado en la evolución de la semántica del cromónimo kenashiri implica el foco de concentración significacional dirigido al color verde y azul verdoso de la hoja de la panca panca, y la relación que se forja con la similaridad de la hoja de pituca (Solari, 2019b: 286). El término asháninka y ashéninka 
https://doi.org/10.46744/bapl.202001.008

kenashiri (en fonemas, /kenaSiri/) es el producto de la adjetivación del sustantivo kenashi (en fonemas, /kenafiri/) que, a su vez, proviene del término protoasháninka/kinajiri/, producto de la lexicalización de $* /$ kina/ y el clasificador para hoja $* /-\int i /$ (ambos provenientes de los términos $* / \mathrm{kịna} / \mathrm{y} * / \int \mathrm{i} /$ del protoarawak preandino, y que habrían representado una planta medicinal en general o una especie desconocida y un ente que termina en forma de punta), donde ya se había formado el concepto de un ente que cura y cuya manifestación física está bajo la forma de hierba.
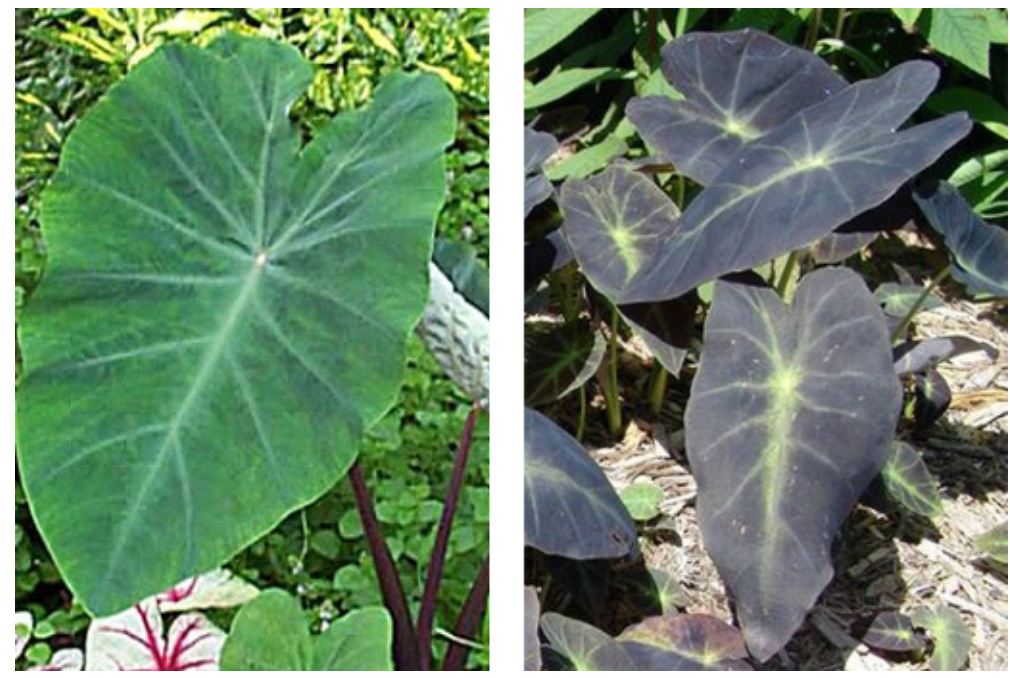

Figura 4. Hojas de pituca (Colocasia esculenta) — a la izquierda — y de la panca panca (Xanthosoma poeppigii Schott) —a la derecha—. Adaptado de «http:// www.selvanet.com.pe/2010/10/la-pituca-o-tarocolocasia-esculenta.html» (imagen de la izquierda) y «http://plantas.facilisimo.com/oreja-de-elefantepara-el-jardin-o-para-el-interior-de-tu-casa_184017.html» (imagen de la derecha). Citado en Solari (2019b: 285).

En protoasháninka y en la primera etapa de desarrollo de sus lenguas hijas, el asháninka y ashéninka, kenashiri habría significado 
literalmente 'el color de la hoja de la panca panca', lo que revelaría su condición de protocromónimo, es decir, un adjetivo que califica un ente a través del color que se percibe en él. Solari (2019b: 304) afirma que cuando un término es considerado un protocromónimo, «ese término no puede ser considerado un término cromático per se, sino que aún se encuentra en la fase de descriptor visual, un término que describe el aspecto cromático de un elemento fijo». Si una lengua, sea en la etapa de desarrollo conceptual en que estuviese, no tiene un término genérico que represente el concepto abstracto color, podría solamente tener descriptores visuales que califiquen una característica de ella a través de la característica visual cromática de un referente en particular, por lo que aquellos que estén establecidos en el habla colectiva serían protocromónimos. Posteriormente, si el significado de los descriptores visuales se generaliza, desligándose de su referente etimológico, estos términos ya podrían ser considerados como cromónimos, siempre y cuando el concepto abstracto color se haya generado en la lengua. Entonces, kenashiri es el producto de la metonimia UNA especie de planta por el Color de las hojas (esa especie De) Planta, donde la semántica actual de este cromónimo básico mantuvo la noción del color verde-azulado de las hojas de esa planta para calificar todos los entes (en muchos casos, exceptuando entes de origen vegetal) que sean verdes.

Se postula que kenashiri se encuentra en una etapa de transición tardía que comenzó hace más de un siglo, cuando el asháninka estuvo en la necesidad de calificar un color como el de las hojas de los árboles o arbustos y cuando comenzó a emplear el tinte verde. Al emplearse kenashiri como color que se diferencia del negro, se generó otra categoría cromática. De ahí se desprende que, en un pasado remoto, en la etapa del protoasháninka preandino, los cromemas que pertenecían al verde eran percibidos como negro; es decir, no había categoría VIRIDIS y todos los cromemas que actualmente pertenecen a esta categoría estaban dentro de la protocategoría NIGER-VIRIDIS-CAERULEUS, conocida en inglés como BLACK-GREEN-BLUE $(\mathrm{Bk} / \mathrm{G} / \mathrm{Bu})$ según la terminología empleada en la segunda revisión de la teoría de los colores básicos ( $c f$. Kay, Berlin, Maffi y Merrifield, 1997). 
https://doi.org/10.46744/bapl.202001.008

\subsection{Etimología y desarrollo semántico de los términos secundarios de la categoría VIRIDIS}

\subsubsection{Los términos matsiriari y natsiriari}

El cromónimo asháninka matsiriari (y su variante atsiriari, producto de una aféresis) y el ashéninka natsiriari son el producto de la evolución del término protoasháninka natsiriari. No se descarta que haya existido una variante con la consonante nasal labializada (matsiriari) dentro de esa etapa de la protolengua. Su empleo en el dialecto asháninka del río Ene es casi nulo. Su reconstrucción etimológica se realiza con la ayuda de los datos disponibles que se tienen de las lenguas arawak preandinas como la matsigenka.

\section{Tabla 3}

Cuadro comparativo del término secundario "matsiriari" y "natsiriari" para la categoría VIRIDIS. Adaptado de Solari (2019b: 279)

\begin{tabular}{|c|c|c|c|c|c|c|c|c|}
\hline \multirow{2}{*}{$\begin{array}{c}\text { Caste- } \\
\text { llano }\end{array}$} & \multicolumn{8}{|c|}{ Macrolengua asháninka } \\
\cline { 2 - 8 } & \multicolumn{3}{|c|}{ Lengua asháninka } & \multicolumn{5}{c|}{ Lengua ashéninka } \\
\cline { 2 - 9 } & SA & TB & EN & RA & PE & PI & GP & AP \\
\hline \multirow{3}{*}{ verde } & matsiriari & matsiriari & - & - & - & - & - & - \\
& - & atsiriari & - & atsiri- & - & - & - & - \\
& - & - & - & ari & natsiriari & natsiriari & natsiriari & natsiriari \\
& & & & - & & & & \\
\hline
\end{tabular}

Para la reconstrucción de este cromónimo, debe recurrirse a los cognados existentes (totales o parciales) en las otras lenguas arawak preandinas:

Tabla 4

Cuadro comparativo del término secundario "matsiriari" y "natsiriari" para la categoría VIRIDIS. Adaptado de Solari (2019b: 287)

\begin{tabular}{|c|c|c|c|c|c|c|c|}
\hline $\begin{array}{c}\text { Caste- } \\
\text { llano }\end{array}$ & $\begin{array}{c}\text { Ashé- } \\
\text { ninka }\end{array}$ & Asháninka & Kakinte & $\begin{array}{c}\text { Nomatsi- } \\
\text { genga }\end{array}$ & Matsigenka & Nanti & $\begin{array}{c}\text { Protoarawak } \\
\text { preandino }\end{array}$ \\
\hline verde & /natsiriari/ & $\begin{array}{c}\text { /matsiriari// } \\
\text { atsiriari/ }\end{array}$ & - & - & /natsiriyari/ & $\begin{array}{c}\text { /natsiriyari/ } \\
\text { ¿? }\end{array}$ & */natsiriza-ri/ \\
\hline
\end{tabular}


Este cromónimo hace referencia a la cualidad de verde aplicada especialmente a las plantas y sus partes, como las hojas, el tallo y el color de los frutos en una determinada etapa de crecimiento. Se evidencia un cognado en la lengua matsigenka (y posiblemente sea el mismo en nanti, dado que son lenguas con un nivel medianamente alto de coincidencia léxica), /natsiriyari/, término que hace referencia a la cualidad púrpura-negruzca de la piel de la persona, en especial, en el rostro, producto de la afectación de algún suceso negativo como el infectarse de sarna u otra enfermedad cutánea (cf. Snell, Chávez, Cruz, Collantes y Pereira 2011: 292); a su vez, este es el producto de la adjetivación de /natsiriya/, término que hace referencia a esa gama de colores oscuros ( $c f$. Snell et al. 2011: 292, 327). No obstante, solo en sus formas flexionadas y derivadas /o-națiriya-i-taya/ y /o-natsiriza-pa-taya/, el lexema matsigenka/natsiriya/ refiere a la cualidad verduzca de las frutas medianas y los plátanos, respectivamente. Por tanto, a partir de estas acepciones en sus formas modificadas morfológicamente, el sentido genérico del lexema /natsiriya/ habría hecho referencia a la coloración oscura de un ente afectado por algún suceso, posiblemente debido a causas naturales o por un suceso negativo. A partir de todos estos datos, se procede con la reconstrucción etimológica del término secundario matsiriari y natsiriari.

En protoarawak preandino, el término */natsiriya/ fue un protolexema que habría referido a la coloración oscura de un ente (de morado a negro) por causas naturales debidas a un desarrollo etario o por un suceso negativo. En protoasháninka, este evoluciona a */națiria/ (forma que se establece posteriormente en la lengua ashéninka), lo que mantiene la noción de la coloración oscura de un ente, en esta etapa, dentro de las tonalidades del verde. Otra de las evidencias que se tiene sobre el surgimiento de las variantes por orden cronológico es el hecho de que Leclerc y Adam (1890: 100) registran < nachiriari> (escrito en la ortografía oficial como nachiriari o natsiriari, según la pronunciación del usuario); posteriormente, Delgado (1897: 351) registra «nachiriari», que demuestra aparentemente una pronunciación antigua del término con la consonante africada palatal sorda (es decir, /nat $\left.\int i r i a r i /\right)$, lo que se confirma con el registro que hace Sala (1905: 194) a partir del mismo término. 
https://doi.org/10.46744/bapl.202001.008

Más adelante, se genera un alternante, */matsiria/, forma que se establece en la lengua asháninka. La coincidencia semántica con el cognado matsigenka se da, como se señaló antes, cuando en esta lengua el término se encuentra en su forma flexionada y derivada ( $c f$. Solari, 2019b: 287-288).

El cambio semántico en el desarrollo del término matsiriari y natsiriari es el siguiente (Solari, 2019b: 289):

\begin{tabular}{|c|c|c|}
\hline $\begin{array}{l}\text { coloración oscura en } \\
\text { an ente en sentido } \\
\text { hegativo' }\end{array}$ & $>$ & $\begin{array}{l}\text { 'coloración } \\
\text { verduzca } \\
\text { en un ente' }\end{array}$ \\
\hline
\end{tabular}

El desarrollo unidireccional evidenciado en la evolución semántica del concepto 'verde', aplicado a las partes de las plantas que tengan esa tonalidad (como las hojas o la cáscara de los frutos en una determinada etapa de crecimiento), va desde la noción de coloración oscura hasta especificarse en la tonalidad verduzca (Solari, 2019b: 289).

\subsubsection{Los términos eereki y eerepa}

En la lengua asháninka y ashéninka, se describen los frutos que recién están brotando y que tienen una coloración verduzca a través del lexema $<$ eere $>$.

\section{Tabla 5}

Cuadro comparativo del término secundario "eereki" y "eerepa" para la categoría VIRIDIS. Adaptado de Solari (2019b: 279)

\begin{tabular}{|c|c|c|c|c|c|c|c|c|}
\hline \multirow{2}{*}{ Castellano } & \multicolumn{6}{|c|}{ Macrolengua asháninka } \\
\cline { 2 - 8 } & \multicolumn{5}{|c|}{ Lengua asháninka } & \multicolumn{4}{c|}{ Lengua ashéninka } \\
\cline { 2 - 8 } & SA & TB & EN & RA & PE & PI & GP & AP \\
\hline $\begin{array}{c}\text { verde (in- } \\
\text { maduro) }\end{array}$ & $\begin{array}{c}\text { eereki } \\
\text { eerepa }\end{array}$ & $\begin{array}{c}\text { eereki } \\
\text { eerepa }\end{array}$ & $\begin{array}{c}\text { eereki } \\
\text { eerepa }\end{array}$ & $\begin{array}{c}\text { eereki } \\
\text { eerepa }\end{array}$ & $\begin{array}{c}\text { eereki } \\
\text { eerepa }\end{array}$ & $\begin{array}{c}\text { eereki } \\
\text { eerepa }\end{array}$ & $\begin{array}{c}\text { eereki } \\
\text { eerepa }\end{array}$ & iiriki \\
iiripa \\
\hline
\end{tabular}


Para la reconstrucción de este cromónimo, debe recurrirse a los cognados existentes (totales o parciales) en las otras lenguas arawak preandinas:

Tabla 6

Cuadro comparativo del lexema <eere $>$ de donde se derivan los términos "eereki" y "eerepa", ambos pertenecientes a la categoría VIRIDIS. Adaptado de Solari (2019b: 290)

\begin{tabular}{|c|c|c|c|c|c|c|c|}
\hline Castellano & $\begin{array}{c}\text { Ashé- } \\
\text { ninka }\end{array}$ & $\begin{array}{c}\text { Ashá- } \\
\text { ninka }\end{array}$ & Kakinte & $\begin{array}{c}\text { Nomat- } \\
\text { sigenga }\end{array}$ & $\begin{array}{c}\text { Matsi- } \\
\text { genka }\end{array}$ & $\begin{array}{c}\text { Nanti } \\
\text { Protoarawak } \\
\text { preandino }\end{array}$ \\
\hline $\begin{array}{c}\text { noción de } \\
\text { alg0 que } \\
\text { recién nace }\end{array}$ & lére/ & lére/ & lére/ & - & - & - & */eire/ \\
\hline
\end{tabular}

Estos dos cromónimos (eereki y eerepa) hacen referencia a la cualidad de verde aplicada especialmente a las plantas y sus partes, como las hojas, el tallo y el color de los frutos en una determinada etapa de crecimiento. Son unos de los pocos cromónimos que tienen forma sustantiva. Para su reconstrucción, debe partirse directamente de los componentes fosilizados que presentan estos dos términos, dado que no presentan cognados en las otras lenguas arawak preandinas y, para llegar hasta la forma que habrían tenido en el protoarawak preandino, debe reconstruirse el lexema $<$ eere $>$. En asháninka y ashéninka, este lexema indica la noción de un ente que recién nace o está en etapa temprana de crecimiento, aunque solamente se emplea con sufijos fósiles, nunca independientemente. Sin embargo, Sala (1905: 194) registra el término «eere» (escrito en la ortografía oficial como eere y representado fonémicamente como /erre/) con el significado de 'verde', 'estar verde' y 'color verde'. Aparentemente, hasta hace aproximadamente un siglo, "eere» era un sustantivo que habría referido a un ente verde y un adjetivo que calificaba el color verde de un ente.

La semántica de <eere> se fundamenta, según Solari (2019: 291), en el significado de los términos asháninka y ashéninka que tienen el mismo lexema, tales como como eentsi (niño/a), eereki (tierno recién brotado, verde), eereshi (hoja tierna, recién brotada), eeretaantsi (brotar, ser tierno, ser verde) y eeretsoba (hoja de la palmera que recién brota) (Payne, 1980: 60-61), en los 
https://doi.org/10.46744/bapl.202001.008

que el sentido de 'recién brotado' o 'algo que está en un estadío temprano de maduración' recae en el lexema <eere $>$. La reconstrucción del lexema del protoarawak preandino */ei-re/ parte del hecho de que */re/ habría significado cualquier ente percibido a la vista, mientras que */e:/ habría concentrado el significado de algo que recién ha nacido o se encuentra en la etapa más precoz del crecimiento.

Para los frutos, generalmente los redondos, se emplea eereki - literalmente significa 'fruto recién nacido'- y para los frutos largos (por ejemplo, el plátano), se emplea eerepa — literalmente significa 'fruto largo recién nacido'). Algunos hablantes emplean indistintamente ambos términos (Solari, 2019b: 291). Esta acepción se evidenciaba desde hace más un siglo, a través de la recopilación de Leclerc y Adam (1890: 95), donde registran «eere-te» (escrito en la ortografía oficial como eereti y que se interpreta actualmente como 'la cubierta verde de un fruto', 'cáscara de un fruto') para 'estar verde la fruta', y «eripengui» (escrito en la ortografía oficial como eerebenki y que se interpreta actualmente como 'planta cuyas hojas verdes recién brotan') para 'verde'. Esta última entrada la registra también Delgado (1897: 351) con el mismo significado. Empero, Delgado también registra «airiki» (escrito en la ortografía oficial como eereki), donde por primera vez se hace referencia al color verde a partir de la coloración de la cáscara del fruto cuando está inmaduro. Años más tarde, Sala (1905: 194) registra también los términos que tienen el lexema <eere> como «eirisch» (escrito en la ortografía oficial como eereshi) — quizá motivado por la referencia al color de la hoja que recién brota-, <eere > (escrito en la ortografía oficial como eere), y también se registran verbos referentes al verde como «eirisch sitaca» (escrito en la ortografía oficial como eereshitsitake) y «eerete» (escrito en la ortografía oficial como eereti), ambos como 'verdear'. Sin embargo, eereti debe interpretarse actualmente como 'la cubierta verde (de la fruta)'.

Los términos eereki y eerepa no cumplen con los requisitos para ser considerados colores básicos (Solari, 2019b: 291). No son monolexémicos porque su significado es predecible a través del significado de sus partes, a pesar de que, en estos casos, $<-k i>$ y $<$-pa $>$ son sufijos que se han 
fosilizado al lexema $<$ eere $>$, y su aplicación está restricta a una clase estrecha de objetos, como los frutos.

El cambio semántico en el desarrollo de los términos eereki y eerepa es el siguiente (Solari, 2019b: 292):

$$
\text { 'algo que recién nace' }>\begin{aligned}
& \text { 'algo que recién } \\
& \text { nace' } \\
& \text { 'algo verde' }
\end{aligned}>\begin{aligned}
& \text { 'algo que recién } \\
& \text { nace' } \\
& \text { 'algo verde' }
\end{aligned}
$$

Se evidencia el desarrollo unidireccional en la evolución del sentido del lexema <eere $>$ y en sus dos manifestaciones sustantivales con función adjetival eereki y eerepa. La formación de estos cromónimos es producto de la metonimia LA FRUTA INMADURA POR EL COLOR VERDE DE LA CÁSCARA DE LA FRUTA INMADURA, en donde el foco atencional es el color del fruto cuyo desarrollo físico es de poco tiempo. En un pasado remoto, estos términos habrían referido solamente a un fruto que recién brota y, en los últimos siglos, la semántica de estos términos se habría extendido al color de ese fruto que recién brota que, en la mayoría de los casos conocidos, es verde (Solari, 2019b: 292).

\subsection{Estructura interna de la categoría CAERULEUS}

A través de la teoría de los prototipos, se presenta el siguiente esquema donde se expone la estructura interna de esta categoría: 


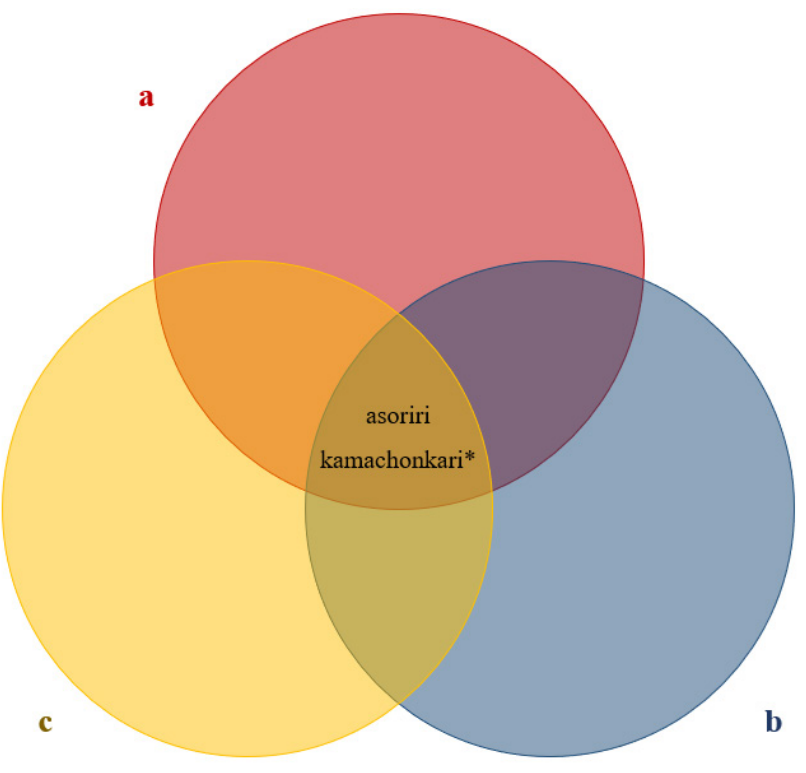

Figura 5. Estructura interna de la categoría CAERULEUS según la teoría de prototipos. Los atributos de esta categoría están representadas a través de conjuntos, donde «a» equivale a los cromónimos cuyos cromemas pertenecen al campo del color azul; «b» equivale a los cromónimos cuya aplicación calificativa a diferentes contextos no es limitada, $\mathrm{y}$ «c» equivale a los cromónimos que no limitan con otras categorías. Adaptado de Solari (2019: 297).

En la lengua asháninka, la categoría CAERULEUS carece de estabilidad porque no todos los hablantes reconocen sus términos relacionados al grupo de cromemas que los hispanohablantes denominarían azul. En la lengua ashéninka, esta categoría se hace evidente porque la mayoría de sus hablantes emplean un hispanismo para calificar los entes que se perciben azules, asoriri (Solari, 2019b: 297). En el macrodialecto asháninka, este término es reconocido por pocos hablantes, por lo que se resalta su carácter de inestable y, en el caso de la mayoría de hablantes de este macrodialecto, una categoría inexistente, a excepción del dialecto 
ashéninka del río Apurímac donde se evidencia que esta categoría es estable por la existencia de un término básico, kamachonkari. Esta categoría no tiene términos secundarios (Solari, 2019b: 298).

\subsection{Etimología y desarrollo semántico del término básico de la ca- tegoría CAERULEUS}

El cromónimo que agrupa los cromemas que los hispanohablantes denominan azul tiene las siguientes formas en la lengua ashéninka y en un dialecto en particular de la lengua asháninka:

Tabla 7

Cuadro comparativo del término básico "asoriri" y "kamachonkari" para la categoría CAERULEUS. Adaptado de Solari (2019b: 281)

\begin{tabular}{|c|c|c|c|c|c|c|c|c|}
\hline \multirow{3}{*}{$\begin{array}{l}\text { Caste- } \\
\text { llano }\end{array}$} & \multicolumn{8}{|c|}{ Macrolengua asháninka } \\
\hline & \multicolumn{4}{|c|}{ Lengua asháninka } & \multicolumn{4}{|c|}{ Lengua ashéninka } \\
\hline & SA & $\mathrm{TB}$ & $\mathrm{EN}$ & RA & $\mathrm{PE}$ & PI & GP & AP \\
\hline \multirow{3}{*}{ azul } & $\begin{array}{c}\text { kenas- } \\
\text { hiri }\end{array}$ & $\begin{array}{c}\text { kenas- } \\
\text { hiri }\end{array}$ & $\begin{array}{c}\text { kenas- } \\
\text { hiri }\end{array}$ & - & \multirow[t]{2}{*}{ asoriiri } & \multirow[t]{2}{*}{ asoriri } & \multirow[t]{2}{*}{ asoriti } & \multirow{2}{*}{$\begin{array}{c}\text { asoriri } \\
\text { ¿? }\end{array}$} \\
\hline & asoriri* & asoriri* & $\begin{array}{c}\text { asori- } \\
\mathrm{ri}^{*} \\
\end{array}$ & - & & & & \\
\hline & - & - & - & kamachonkari & kamachonkari & - & - & - \\
\hline
\end{tabular}

El asterisco a la derecha del término asoriri en los casilleros correspondientes a la lengua asháninka señala que pocos hablantes reconocen la existencia de esta categoría (por consiguiente, de este término prestado del castellano). Empero, debe recordarse que esta categoría no es estable (cf. Solari, 2019b: 294) porque la mayoría de hablantes de esta lengua no la reconocen como válida, pues consideran los cromemas $\mathbf{\square}, \mathbf{\square}, \mathbf{\square}$ y $\mathbf{\square}$ (y aquellos derivados que se acercan más al color que los hispanohablantes denominan verde, negro y púrpura) como kenashiri, es decir, pertenecientes a la categoría VIRIDIS.

En el caso de kamachonkari, se señala que el término que está dentro del casillero que señala el dialecto ashéninka del Alto Perené no es un 
cromónimo, sino un zoónimo empleado en esta región que hace referencia a una especie de mosquito. Solo pocos hablantes lo consideran como un protocromónimo. En el dialecto asháninka del río Apurímac, es el cromónimo básico de la categoría CAERULEUS.

Para la reconstrucción de estos dos cromónimos, debe recurrirse a los cognados existentes (totales o parciales) en las otras lenguas arawak preandinas:

Tabla 8

La reconstrucción del término básico de la categoría CAERULEUS en la lengua ashéninka. Adaptado de Solari (2019b: 283)

\begin{tabular}{|c|c|c|c|c|c|c|c|}
\hline $\begin{array}{c}\text { Caste- } \\
\text { llano }\end{array}$ & $\begin{array}{c}\text { Ashé- } \\
\text { ninka }\end{array}$ & $\begin{array}{c}\text { Ashá- } \\
\text { ninka }\end{array}$ & Kakinte & $\begin{array}{c}\text { Nomatsi- } \\
\text { genga }\end{array}$ & $\begin{array}{c}\text { Matsi- } \\
\text { genka }\end{array}$ & Nanti & $\begin{array}{c}\text { Origen del } \\
\text { término }\end{array}$ \\
\hline azul & /asoriri/ & lasoriri/ & - & - & - & - & esp. lat. /asul/ \\
\hline
\end{tabular}

El cromónimo asoriri es un producto del intercambio cultural y lingüístico entre la población asháninka e hispanohablante, tanto por el contacto que entablaron los españoles en la época virreinal y, en menor medida, los llamados «criollos» en la época republicana, como por el contacto con los migrantes andinos que llevan consigo el habla castellana, también «colonos». En su forma lexemática, asori es la adaptación del cromónimo castellano azul. Al agregar el sufijo adjetival <-ri $>$, se genera el significado 'cualidad de asori'. Es empleado principalmente en la lengua ashéninka por los hablantes que ya la han diferenciado claramente de los cromemas del verde, y uno de los motivos más importantes es la introducción del tinte artificial de color azul en la sociedad asháninka, que se manifiesta a través de las ropas occidentales que algunos pobladores visten (Solari, 2019b: 294). 
Tabla 9

La reconstrucción del término básico de la categoría CAERULEUS en la lengua ashéninka. Adaptado de Solari (2019b: 294)

\begin{tabular}{|c|c|c|c|c|c|c|c|}
\hline $\begin{array}{l}\text { Caste- } \\
\text { llano }\end{array}$ & Ashéninka & Asháninka & Kakinte & $\begin{array}{l}\text { Nomat- } \\
\text { sigenga }\end{array}$ & Matsigenka & Nanti & $\begin{array}{c}\text { Protoarawak } \\
\text { preandino }\end{array}$ \\
\hline $\begin{array}{l}\text { azul, } \\
\text { celeste }\end{array}$ & $\mid k$ kamatfonkarip| & 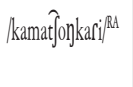 & |kamat]onkaril & - & |kamat]onkkari| & - & */kamatjoNka-iil \\
\hline
\end{tabular}

La acepción que presenta el término kamachonkari en la lengua asháninka es distinta de la que presenta en la lengua ashéninka. Las razones se definen, en primer lugar, en que este término funciona como cromónimo en solo un dialecto (el asháninka del río Apurímac) y no se descarta que la cercanía geográfica de sus hablantes con aquellos que hablan la lengua matsigenka influyera en su semántica, dado que en esta otra lengua arawak, hablada en el departamento de Cusco, también es un cromónimo que hace referencia a una gama de colores que abarca desde las tonalidades verdeazulinas hasta las azules, sea cual fuere el grado de brillo; es decir, lo que los hispanohablantes denominarían azul, celeste y verde-azulino o azul verduzco. La acepción ya se había confirmado hace más de un siglo a través del registro de Wiener (1880: 789) y Touchaux (1890: 11), donde recopilan para azul «camachuneari» (una representación ortográfica errada de kamachonkari; posiblemente, por cuestiones de error de imprenta, confundieran $<_{c}>$ por $\left\langle\mathrm{e}>\mathrm{y}<_{\mathrm{o}}\right\rangle_{\text {por }}<_{\mathrm{u}}>$, aunque este último caso podría haberse debido a que algunos hablantes, como hasta el día de hoy, pronuncian la vocal baja /o/ con el rasgo [+alto], es decir, como [o], [u] o [u]). En segundo lugar, se observa que en el dialecto ashéninka del Alto Perené este término hace referencia a una especie de insecto «cuyo efecto de su orina en la piel de la persona cuando esta se posa en ella es de un ardor muy intenso y se observa una mancha de una coloración rojiza» (Solari, 2019b: 295). Esta acepción de kamachonkari en el dialecto ashéninka del Alto Perené evidencia una cierta correspondencia con el cognado kakinte. En esta otra lengua arawak, el lexema /kamat $\mathrm{oNk} /$ hace referencia al color de la sangre cuando es oscura. Por lo tanto, hasta este momento, el lexema da una pista sobre un posible significado en una etapa anterior de estas lenguas. 
https://doi.org/10.46744/bapl.202001.008

Las acepciones que se tienen de kamachonkari en el dialecto asháninka del río Apurímac y en el dialecto ashéninka del Alto Perené y del lexema / kamat $0 \mathrm{Nka} /$ en kakinte nos remitirían a que este lexema en protoarawak preandino, es decir, */kąmat $\widehat{0} \mathrm{oNka} /$, habría hecho referencia a la noción de un color con un bajo grado de brillo, extendido desde el rojo oscuro hacia el azul. Habría la posibilidad de que el término protoarawak preandino */

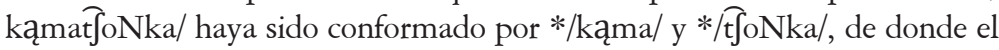
primer protolexema evoluciona, a través de la fosilización del sufijo */-ra/, en asháninka a /kamara/, cuya adjetivación (/kamarari/) hace referencia al color marrón; en matsigenka, en el lexema/kamara/ y en el cromónimo/kamarari/, y en nomatsigenga, en el lexema/komara/y en el cromónimo/komarari/. De ahí que el símbolo /ą/ en */kąmaţoNka/ signifique una vocal central baja no redondeada (es decir, /a/) que, solo en una de sus evoluciones según la lengua (en este caso, en nomatsigenga), gana el rasgo de posterioridad y labial, que se convierte en vocal posterior redondeada. Se desconoce, por el momento, la semántica de la protoforma $* / \widehat{t}_{\mathrm{J}} \mathrm{Nka} /$ por falta de datos disponibles.

A partir de */kąmat 0 oNka/ y su relación con los cognados del cromónimo asháninka y ashéninka kamarari, debe remitir a la idea de que la protoforma $* / \mathrm{kąma} /$ hiciera referencia a un ente o el color de un ente que presenta un bajo grado de brillo y que abarca una gama de colores que los hispanohablantes denominan rojo, marrón y azul.

El cambio semántico en el desarrollo del término kamachonkari en la lengua asháninka y ashéninka es el siguiente (Solari, 2019: 296):

$\begin{array}{lll}\begin{array}{l}\text { 'color de } \\ \text { bajo brillo' }\end{array} & \begin{array}{l}\text { 'color que va desde el } \\ \text { verde azulado hacia } \\ \text { el azul' (asháninka) }\end{array} & \begin{array}{l}\text { 'azul' } \\ \text { (asháninka RA) }\end{array} \\ \begin{array}{l}\text { 'ente con } \\ \text { colores de } \\ \text { bajo brillo' }\end{array} & \begin{array}{l}\text { insecto cuyo efecto } \\ \text { de su secreción en la } \\ \text { piel es la generación } \\ \text { de una mancha } \\ \text { rojiza' (ashéninka) }\end{array} & \begin{array}{l}\text { 'insecto cuyo efecto } \\ \text { de su secreción en la } \\ \text { piel es la generación } \\ \text { de una mancha rojiza' } \\ \text { (ashéninka PE) }\end{array}\end{array}$


Si se parte del protoasháninka, la posible acepción de */kąmat $\widehat{t}$ oNka/ habría remitido a un ser animado con colores (o características visuales) que habrían variado entre el rojo, marrón y azul. Desde la etapa del protoasháninka, */kamat $\widehat{o N k a}_{\mathrm{N}}$ habría sido un protocromónimo que denominaba una especie de animal — a partir de la acepción en el ashéninka del Alto Perené, una especie de insecto de la cual se desconoce el nombre científico-y que hacía referencia a la cualidad cromática de aquel insecto. Por contacto lingüístico, en el asháninka del río Apurímac, kamachonkari recibe del cognado matsigenka la acepción de hacer referencia al color azul, dado que, en el caso de esta lengua, prima la evolución que habría partido de la referencia a un color que excluía el color rojo y marrón, por lo que se limitaba a las tonalidades azulinas.

\section{Conclusiones}

Uno de los argumentos que podría jugar a favor de diferenciar la lengua asháninka de la ashéninka y no considerarlas como una sola lengua es el hecho de que los límites de la categoría VIRIDIS (referente al color verde) en cada lengua son diferentes, lo que genera en el ashéninka y en el asháninka del río Apurímac la categoría CAERULEUS (referente al color azul).

La necesidad del empleo del tinte azul generalizado entre varias comunidades ashéninkas, además del contacto cuasicontinuo con la población hispanohablante y el contacto que tienen a menudo los hablantes del asháninka del río Apurímac con la población matsigenka, habría generado la aparición de la categoría que clasifica la terminología referente al color azul.

El cromónimo kenashiri —y su variante geodialectal kinashiri_ basa su semántica a partir de la característica verduzca-azulina de las hojas de la panca panca, la que posteriormente se extiende a calificar cualquier ente que sea verde.

El cromónimo matsiriari (en asháninka) y natsiriari (en ashéninka) habría sido el resultado de la percepción de una coloración oscura en un ente y trasladado a la coloración verduzca de las plantas y frutos cuando se encuentran en una etapa anterior a la madurez. 
Los cromónimos eereki y eerepa parten del sentido de que algo recién nace o brota, sentido que se traslada al nacimiento o brote de los frutos, en donde el foco atencional es el color verduzco de estos cuando se encuentran en esta etapa temprana de desarrollo.

El cromónimo asoriri es una adaptación del término hispano azul para calificar los entes de ese color, que se produce por una necesidad de la población de calificar los entes que tienen ese color, cuyo tinte empleado para colorearlos es artificial, generalmente.

La semántica del cromónimo kamachonkari habría partido desde la referencia hacia un ente cuya gama cromática tuviera un bajo grado de brillo, que abarcaría el rojo, marrón y azul. El sentido de referencia hacia un ente queda evidente en el dialecto ashéninka del Alto Perené, donde el foco atencional es la mancha rojiza que una especie de insecto deja en la piel de la persona a través de su picadura. En cambio, en asháninka del río Apurímac, hace referencia a la gama de colores del azul, que mantiene la noción pasada de la cualidad de un ente caracterizado por el bajo brillo que presenta. 
https://doi.org/10.46744/bapl.202001.008

\section{BIBLIOGRAFÍA}

BERLIN, B. \& KAY, P. (1969). Basic color terms: their universality and evolution. Berkeley \& Los Angeles, Estados Unidos: University of California Press.

CUENCA, M. J. \& HILFERTY, J. (1999). Introducción a la lingüística cognitiva. Barcelona: Editorial Ariel, S. A.

DELGADO, E. (1897). Vocabulario del idioma de las tribus campas. Boletín de la Sociedad Geográfica de Lima, 6(6), 96-105, 230-240 y 347-356.

ELVIRA, J. (en prensa). Aproximación al concepto de lexicalización. En J. Rodríguez Molina y DM Sáez Rivera (Eds.). Diacronía, lengua española y lingüística, pp. 21-41. Madrid: Síntesis. Recuperado de https://www.uam.es/personal_pdi/filoyletras/ javel/lexicalizacion.pdf

GARCÍA ZAVALETA, C. (1987). Estudio Exploratorio de las Prácticas Tradicionales en Salud del Grupo Étnico Campa-Ashaninka en el Valle del Pichis: Recursos Empleados en Salud Bucal (Tesis de Bachiller). Universidad Peruana Cayetano Heredia.

INEI (2018). Censos Nacionales 2017: XII de Población, VII de Vivienda y III de Comunidades Indígenas. Lima, Perú: Dirección Técnica de Demografía y Estudios Sociales y Centro de Investigación y Desarrollo del Instituto Nacional de Estadística e Informática (INEI). Recuperado de https://www.inei.gob. pe/media/MenuRecursivo/publicaciones_digitales/Est/ Lib1539/libro.pdf

JACINTO, P. (2019). Primer Informe: Pueblo asháninka. Manuscrito presentado para su publicación.

KAY, P., BERLIN, B., MAFFI, L. y MERRIFIELD, W. (en prensa). Color Naming Across Languages. Color Categories in Thought and 
https://doi.org/10.46744/bapl.202001.008

Language. Recuperado de www1.icsi.berkeley.edu/ kay/ KBMM.ps

KUEHNI, R. (2008). Why colour words are really ... colour words. Journal of the Royal Anthropological Institute (N.S.), 14, 886-889. Recuperado de http://www1.icsi.berkeley.edu/ kay/wierz. colour.comment.pdf

. La Pituca o Taro: Colocasia esculenta. (20 de agosto de 2017). SelvaNet. Recuperado de http://www.selvanet. com.pe/2010/10/la-pituca-o-tarocolocasia-esculenta.html. Consultado el 24 de agosto de 2018.

LECLERC, C. \& ADAM, L. (1890). Arte de la lengua de los indios antis o campas. París: J. Maisonneuve.

LUZIATELLI, G., SØRENSEN, M., THEILADE, I. \& MØLGAARD, P. (2010). Asháninka medicinal plants: a case study from the native community of Bajo Quimiriki, Junín, Peru. Journal of Ethnobiology and Ethnomedicine, 6(21), 1-23. Recuperado de https://www.researchgate.net/profile/ Ida_Theilade/publication/293871968_Additional_file_1/ links/56efb58408aea35d5b9a637e/Additional-file-1. pdf?origin $=$ publication_detail

MEDINA, A. (2011). Estudio descriptivo de la frase nominal en el asháninka del Alto Perené (Tesis de licenciatura). Universidad Nacional Mayor de San Marcos. Recuperado de http:// cybertesis.unmsm.edu.pe/bitstream/handle/cybertesis/1228/ Medina_gp.pdf;jsessionid $=$ CABD14E0A108618997A68 BEDE1BFEB15? sequence $=1$

MOHAMMAD, S. (2011). Colourful language: Measuring word-colour associations. Proceedings of the 2 nd Workshop on Cognitive Modeling and Computational Linguistics, pp. 97-106. Ottawa: Association for Computational Linguistics. Recuperado 
https://doi.org/10.46744/bapl.202001.008

de http://www.anthology.aclweb.org/W/W11/W11-06. pdf\# page $=107$

. Oreja de elefante para nuestro jardín. (n.d.). Plantas Facilísimo. Recuperado de http://plantas.facilisimo.com/ oreja-de-elefante-para-el-jardin-o-para-el-interior-de-tucasa_184017.html. Consultado el 24 de agosto de 2018 a las 18:50 horas.

PARODI, F. (2002). La cromosemiótica, el significado del color en la comunicación visual. Comunicación, 2(3). Recuperado de http://sisbib.unmsm.edu.pe/bibvirtualdata/publicaciones/ comunicacion/n3_2002/a07.pdf

ROSCH, E., MERVIS, C. B., GRAY, W. D., JOHNSON, D. M., BOYESBRAEM, P. (1976). Basic objects in natural categories. Cognitive psychology, 8(3), 382-439.

ROSCH, E., \& LLOYD, B. B. (1978). Cognition and Categorization. Recuperado de http://citeseerx.ist.psu.edu/viewdoc/down load? $\mathrm{doi}=10 \cdot 1 \cdot 1 \cdot 307.5210 \& \mathrm{rep}=$ rep $1 \&$ type $=\mathrm{pdf}$

SALA, G. (1905). Diccionario, gramática y catecismo Castellano, Inga, Amueixa y Campa. Lima: Tip. Nacional F. Barrionuevo.

SHAVER, H. (1996). Diccionario Nomatsiguenga-Castellano Castellano Nomatsiguenga. Pucallpa, Perú: Instituto Lingüístico de Verano.

SNELl, B. A., CHÁveZ, I., CRUZ, V., COLlANTES, A., PEREIRA, J, E. (2011). Diccionario matsigenka - castellano con índice castellano, notas enciclopédicas y apuntes gramaticales. En Wise, M. R. (Ed.), Serie Lingüística Peruana (Vol. 56). Recuperado de https://www.sil.org/system/files/reapdata/95/79/38/95793891741272531054477784142915753324/ mcbDIC_press.pdf 
https://doi.org/10.46744/bapl.202001.008

SOLARI, O. (2019a). Los términos para el color blanco y su desarrollo semántico en la lengua asháninka. Manuscrito presentado para su publicación.

. (2019b). Etnosemántica de los colores en la lengua asháninka - una visión cognitiva, sincrónica y diacrónica (Tesis de maestría). Universidad Nacional Mayor de San Marcos. Recuperado de http://cybertesis.unmsm.edu.pe/handle/ cybertesis/11149

SOLARI, O. (2020). Los términos para el color negro y su desarrollo semántico en la lengua asháninka. Manuscrito presentado para su publicación.

STEINVALL, A. (2002). English colour terms in context (Tesis doctoral). Umeå Universitet. Recuperado de http://www.diva-portal. org/smash/get/diva2:144764/FULLTEXT01.pdf

TOUCHAUX, M. (1909). Apuntes sobre la gramática y el diccionario del idioma campa o lengua de los antis tal como se usa en el rio Apurímac. Lima: Imp. Nacional de Federico Barrionuevo. Recuperado de http://etnolinguistica.wdfiles.com/local-files/biblio\%3 Atouchaux-1909-apuntes/Touchaux_1909 Apuntes_harvard.pdf

VALENZUELA, J., IBARRETXE-ANTUÑANO, I., HILFERTY, J. (en prensa). La Semántica Cognitiva. Lingüística Cognitiva. En Ibarretxe-Antuñano, I. \& Valenzuela, J. (Eds.). Lingüística cognitiva. Barcelona, España: Anthropos. Recuperado de: http://www.unizar.es/linguisticageneral/articulos/ValenzuelaIbarretxe-Hilferty-SemCog.pdf

WIENER, C. (1880). Pérou et Bolivie - Récit de Voyage. París, Francia: Typographie A. Lahure. Recuperado de https://issuu.com/ gibergarcia/docs/4._1880_-_charles_wiener_-_P_rou_e_ f9d7f6a1f9a61b 